\title{
Screening blood glucose values: effects of season and time of day
}

\author{
R.J.Jarrett ${ }^{1}$, T.J.Murrells ${ }^{2}$, M.J.Shipley ${ }^{3}$ and T. Hall ${ }^{4}$ \\ ${ }^{1}$ Department of Community Medicine, Guy's Hospital Medical School, ${ }^{2}$ Unit for Metabolic Medicine, Guy's Hospital, \\ ${ }^{3}$ Department of Medical Statistics and Epidemiology, London School of Hygiene and Tropical Medicine and \\ ${ }^{4}$ Greater London Council, County Hall, London, UK
}

Summary. Blood glucose screening results, obtained using two different screening procedures, are reported from two occupational groups. Post-prandial blood glucose levels were measured in 3346 subjects aged 45 years or more employed by the Greater London Council/Inner London Education Authority. In women, mean blood glucose levels were higher in the afternoon than the morning $(p<0.05)$. Ninety-fifth centile levels were substantially higher in the afternoon in both sexes, though the differences were not constant in all age and sex sub-groups. In both sexes mean glucose levels were highest in the winter (December-February, inclusive), but seasonal variation did not significantly affect the proportion exceeding the ninety-fifth centile for the total population. In the Whitehall study, the blood glucose was measured in men, in the morning, $2 \mathrm{~h}$ after a 50 -g glucose load. Significant seasonal variation in mean blood glucose values occurred, with highest values in winter and lowest in spring (March-May, inclusive). However, there was no significant difference by season in the proportions exceeding the arbitrary cut-off levels of 7.8 and $11.1 \mathrm{mmol} / 1$.

Key words: Blood glucose, screening, diabetes mellitus, impaired glucose tolerance, seasonal variation, diurnal variation.
Several recommendations concerning screening for diabetes mellitus arose from a Diabetes Screening Workshop held in Atlanta in 1978 [1]. The participants recommended inter alia that "screening programmes to detect asymptomatic glucose intolerance per se are not recommended as health services in non-pregnant populations" but that "research into the screening process itself was recognised as essential to develop and to assess new procedures and methods of screening, as well as to improve and to refine familiar procedures". In the spirit of the latter recommendation, we present data on certain factors affecting post-prandial and post-load blood glucose levels in two occupational groups.

\section{Subjects and methods}

Since 1970, employees of the Greater London Council and the Inner London Education Authority (GLC/ILEA), aged 45 years or more, may avail themselves of a multiple-test screening programme, which includes a blood glucose measurement [2]. For the purpose of this study we have termed this a post-prandial measurement, though it is not precisely timed in relation to a meal. Nevertheless, it is less well described as a 'casual' or 'random' measurement since it was made at least $2 \mathrm{~h}$ post-prandially. Approximately one-third of those eligible in a given year attended the screening clinic. The volunteers attend a special clinic, usually held on 2 days per week, either in the morning $(09.30-12.00 \mathrm{~h})$ or in the afternoon $(14.00-16.00 \mathrm{~h})$. They are request- ed to have nothing to eat or drink for at least $2 \mathrm{~h}$ before their appointment time.

Capillary blood $(0.1 \mathrm{ml})$ is taken from an ear lobe soon after arrival and added to $0.9 \mathrm{ml}$ of $1 \%$ sodium fluoride. The glucose content is subsequently measured by a modification of the ferricyanide reduction method in an autoanalyser (Model 1, Technicon Instruments, Basingstoke, Hants, UK). To date, all samples have been measured by the same technician on the same apparatus, with quality control checks included in each assay.

The second population comprised male civil servants, aged 40 years or more, working in the vicinity of Whitehall - the Whitehall study, details of which have been published previously [3]. Approximately $80 \%$ of those eligible attended. In this study, participants con-

Table 1. Mean and centile values of post-prandial blood glucose by sex and time of day

\begin{tabular}{llllll}
\hline & \multicolumn{4}{l}{ Post-prandial blood glucose $(\mathrm{mmol} / \mathrm{l})$} \\
\cline { 2 - 3 } & \multicolumn{2}{l}{ Men } & & \multicolumn{2}{l}{ Women } \\
\cline { 2 - 3 } & $\begin{array}{l}\text { Morning } \\
(n=1417)\end{array}$ & $\begin{array}{l}\text { Afternoon } \\
(n=1056)\end{array}$ & & $\begin{array}{l}\text { Morning } \\
(n=277)\end{array}$ & $\begin{array}{l}\text { Afternoon } \\
(n=596)\end{array}$ \\
\hline $5 \%$ & 3.8 & 3.6 & 3.6 & 3.6 \\
$50 \%$ & 4.5 & 4.4 & 4.2 & 4.2 \\
$90 \%$ & 5.2 & 5.4 & 4.8 & 4.9 \\
$95 \%$ & 5.5 & 5.8 & 4.9 & 5.3 \\
$99 \%$ & 6.0 & 6.6 & 5.9 & 6.0 \\
Mean & 4.5 & 4.5 & 4.2 & 4.3 \\
SD & 0.6 & 0.8 & 0.5 & 0.6 \\
SEM & 0.02 & 0.02 & 0.03 & 0.03 \\
\hline
\end{tabular}


Table 2. Mean and centile capillary blood glucose values by age group, sex and time of day

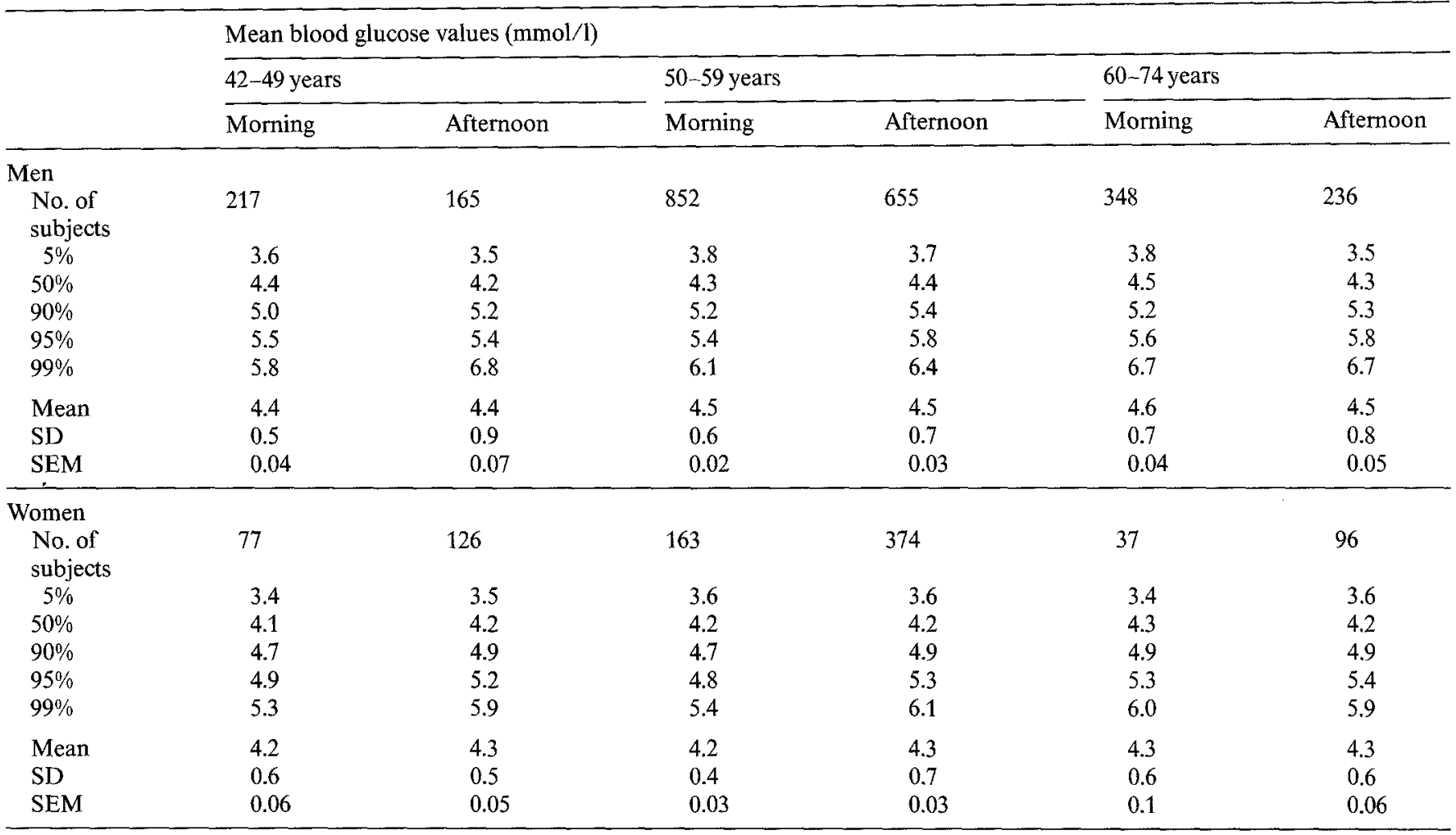

Table 3. Mean age-adjusted post-prandial capillary blood glucose levels by season, time of day and sex

\begin{tabular}{lllllll}
\hline & & \multicolumn{3}{l}{ Blood glucose levels (mmol/1) } \\
\cline { 1 - 4 } \cline { 5 - 7 } Sex & Time of day & & Winter & Spring & Summer & Autumn \\
\hline Men & Morning & $4.7 \pm 0.03$ & $4.5 \pm 0.04$ & $4.5 \pm 0.04$ & $4.5 \pm 0.03$ \\
& & $(n=416)$ & $(n=397)$ & $(n=221)$ & $(n=383)$ \\
& \multirow{2}{*}{ Afternoon } & $4.6 \pm 0.04$ & $4.5 \pm 0.05$ & $4.6 \pm 0.05$ & $4.4 \pm 0.05$ \\
& & $(n=290)$ & $(n=280)$ & $(n=182)$ & $(n=304)$ \\
Women & Morning & $4.4 \pm 0.08$ & $4.2 \pm 0.05$ & $4.3 \pm 0.08$ & $4.1 \pm 0.04$ \\
& & $(n=44)$ & $(n=58)$ & $(n=61)$ & $(n=114)$ \\
& Afternoon & $4.4 \pm 0.05$ & $4.2 \pm 0.04$ & $4.3 \pm 0.06$ & $4.3 \pm 0.06$ \\
& & $(n=155)$ & $(n=156)$ & $(n=109)$ & $(n=176)$ \\
\hline
\end{tabular}

Results expressed as mean \pm SEM with number of subjects in parentheses

Table 4. Comparison of mean post-prandial capillary blood glucose levels in winter with combined values for the other seasons.

\begin{tabular}{lllll}
\hline Sex & \multirow{2}{l}{$\begin{array}{l}\text { Time } \\
\text { of } \\
\text { day }\end{array}$} & \multicolumn{3}{l}{ Mean blood glucose levels (mmol/1) } \\
\cline { 3 - 5 } & & $\begin{array}{l}\text { December- } \\
\text { February }\end{array}$ & \multicolumn{1}{l}{$\begin{array}{l}\text { March- } \\
\text { November }\end{array}$} & t values \\
\hline Men & Morning & 4.7 & 4.5 & $4.77^{\mathrm{a}, \mathrm{b}, \mathrm{c}}$ \\
& Afternoon & 4.6 & 4.5 & $2.15^{\mathrm{a}, \mathrm{d}}$ \\
Women & Morning & 4.4 & 4.2 & $2.19^{\mathrm{a}}$ \\
& Afternoon & 4.4 & 4.3 & $2.66^{\mathrm{a}, \mathrm{b}}$ \\
\hline
\end{tabular}

Glucose values adjusted for age within each group.

${ }^{\mathrm{a}} p<0.05 ;{ }^{\mathrm{b}} p<0.01 ;{ }^{\mathrm{c}} p<0.001$. $^{\mathrm{d}}$ F-test for equality of variances shows that variances are not equal. An approximation to $t$ has been calculated based on a separate variance estimate sumed $50 \mathrm{~g}$ liquid glucose $(235 \mathrm{ml}$ of a proprietary preparation - Lucozade, Beecham Pharmaceuticals, London, UK) in the morning after an overnight fast. Capillary blood was obtained from an ear lobe $2 \mathrm{~h}$ later. Blood glucose was measured by the same autoanalyser method as in the GLC/ILEA study. The observations were made over the period September 1967 to January, 1970.

\section{Statistical analysis}

Statistical tests include Student's t-test for unpaired variables (twotailed) and the $\chi^{2}$ test for proportions.

\section{Results}

\section{Post-prandial blood glucose}

The data include results from all subjects, except previously-known diabetic patients, screened during the 4 years 1975-1978. Mean and centile values of postprandial blood glucose measurements have been calculated in relation to sex, time of day and age category (42-49 years, $50-59$ years and $60-74$ years). In addition, possible seasonal variation has been looked for.

The mean and centile values by sex and time of day, without age adjustment, are shown in Table 1 . Mean values, both morning and afternoon, were higher in men than women. Within the sexes, differences between morning and afternoon levels were small, though the difference was statistically significant in women $(p<$ 0.05 ). Of more significance in terms of screening are the 95th and 99th centile values. Both were substantially 
Table 5. Mean capillary blood glucose measured $2 \mathrm{~h}$ after a 50-g oral glucose load by season of examination: the Whitehall study (normal subjects)

\begin{tabular}{|c|c|c|c|c|}
\hline \multirow{2}{*}{$\begin{array}{l}\text { Age } \\
\text { (years) }\end{array}$} & \multicolumn{4}{|c|}{ Season of examination } \\
\hline & $\begin{array}{l}\text { December- } \\
\text { February }\end{array}$ & March-May & June-August & $\begin{array}{l}\text { September- } \\
\text { November }\end{array}$ \\
\hline $40-49$ & $4.2 \pm 0.02$ & $4.18 \pm 0.02$ & $4.1 \pm 0.02$ & $4.2 \pm 0.01$ \\
\hline $50-59$ & $4.3 \pm 0.02$ & $4.1 \pm 0.02$ & $4.2 \pm 0.03$ & $4.3 \pm 0.02$ \\
\hline $60-64$ & $4.4 \pm 0.05$ & $4.2 \pm 0.06$ & $4.2 \pm 0.06$ & $4.4 \pm 0.04$ \\
\hline Total & $4.3 \pm 0.01$ & $4.1 \pm 0.01$ & $4.2 \pm 0.02$ & $4.3 \pm 0.01$ \\
\hline
\end{tabular}

Results expressed as mean $\pm \mathrm{SEM}$

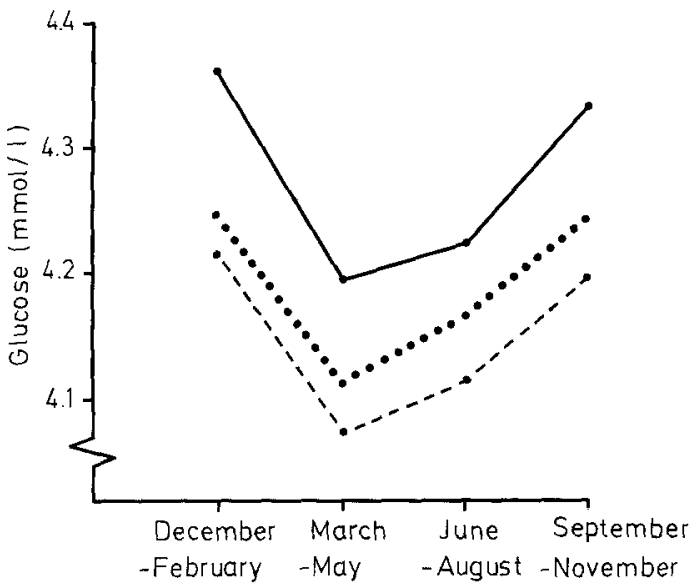

Fig. 1. Whitehall study: mean blood glucose levels by age and season. . - . 4 40-49 years; ...... 50-59 years; $\longrightarrow$ $60-64$ years

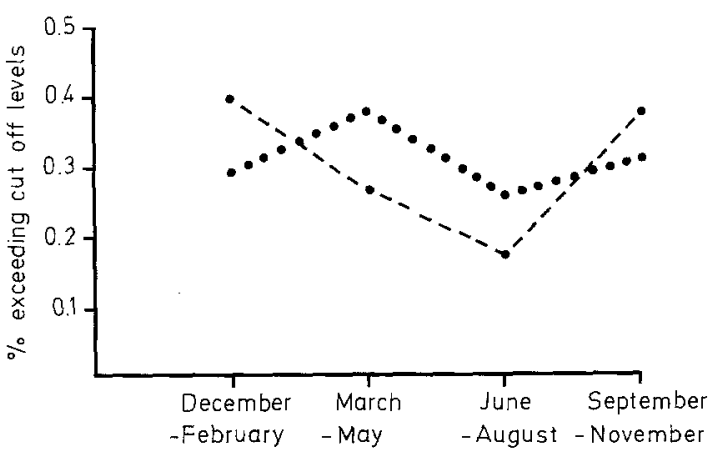

Fig. 2. Whitehall study: proportions exceeding cut-off blood glucose levels for impaired glucose tolerance and diabetes by season. - - - - Impaired glucose tolerance (blood glucose $>7.8$ $\leqslant 11.1 \mathrm{mmol} / \mathrm{l}) ; \ldots \ldots$ diabetes (blood glucose $>11.1 \mathrm{mmol} / \mathrm{l}$ )

different in men between morning and afternoon. The 95 th centile value was substantially different in women.

Mean and centile values with the addition of age categories are presented in Table 2 . In men there was a small increase in mean blood glucose with age, mainly between those below and those above 50 years. The major effect of age, however, was to increase the value of the 99th centile in the morning, whereas the afternoon value was unrelated to age. However, the morning differences were based on small numbers below age
50 years and above age 60 years. In women, sub-division by age results in small numbers in some categories, particularly in those aged over 60 years and tested in the morning. The results are similar to those in men, with a small increase in mean values with age and an age-related increase in the 99th centile value in the morning, with no systematic change in the afternoon. As the standard deviation values indicate, there was a greater degree of variance in the afternoon values, more evidently in men.

We looked for possible seasonal variation by comparing average age-adjusted blood glucose levels in winter (December-February), spring (March-May), summer (June-August) and autumn (September-November) (Table 3). Connoisseurs of the English climate will realise that this is arbitrary! It follows the seasonal division previously used by Suarez and Barrett-Connor [5]. The only consistent finding for both sexes and for morning and afternoon was that the winter averages were the highest. When compared with the averages of the other seasons, these differences were significant (Table 4).

\section{Post-load blood glucose}

The mean blood glucose values in the men in the Whitehall study, categorized by age group and season, are presented in Table 5. There was a small gradient with age within each season, and in all age groups the same pattern is visible (Fig.1), with highest values in winter, lowest values in spring, increasing through summer and autumn. We have further analysed the data to see whether the imposition of cut-off values of $7.8 \mathrm{mmol} / 1(140 \mathrm{mg} / \mathrm{dl})$ and $11.1 \mathrm{mmol} / 1(200 \mathrm{mg} / \mathrm{dl})$ (those recommended by the Expert Committee of the World Health Organisation [4] for consideration as 'impaired glucose tolerance' and 'diabetes', respectively) yielded different proportions in these categories according to the season (Fig.2). (The Expert Committee rounded the SI values to 8.0 and $11.0 \mathrm{mmol} / 1$ respectively). For 'diabetes', there were only modest differences between seasons and the pattern did not correspond with mean values. For impaired glucose tolerance, the pattern was similar to that of the mean values, differing in the spring/summer ratio, but the $\chi^{2}$ test for differences in proportions has a $p$ value $>0.05$.

\section{Discussion}

Measurement of the post-prandial blood glucose has been little used as a screening procedure for diabetes mellitus. The relative convenience and simplicity of the method have presumably been outweighed by doubts concerning standardisation. Previous attempts [6] to estimate the sensitivity and specificity of this (and other) screening methods are no longer valid following the change in recommended diagnostic criteria to higher values [4]. The results from the GLC/ILEA study do 
not in themselves provide the basis for a choice of screening cut-off values, though we hope in future to provide data based upon a comparison of post-prandial and glucose-tolerance-test values. They do, however, indicate that different criteria might be necessary according to the age and sex of the subject and the time of day at which the sample is taken.

The degree of diurnal variation is clearly much less with post-prandial blood glucose values than with postload values [7] and a significant difference between average morning and afternoon values occurred only in women. However, distributions did differ in both sexes between morning and afternoon, particularly in the 95th centile values, a common choice for a screening cut-off level.

Although there is some seasonal effect upon mean glucose levels, this is of minor degree and makes little difference to the proportion screening positive above the 95th centile of the total population in different seasons (data not shown).

A seasonal variation was also apparent in the $2-h$ blood glucose values from the Whitehall study, a pattern identical to that observed for fasting blood glucose levels in Southern California [5]. Although the seasonal differences were statistically significant, the absolute differences were small and did not significantly affect the proportions exceeding the critical cut-off levels (for a 75-g oral glucose load) suggested by the WHO Expert Committee. The value of $11.1 \mathrm{mmol} / 1(200 \mathrm{mg} / \mathrm{dl})$ was actually used in the Whitehall study to indicate diabetes and was ultimately justified by the observation that clinically significant diabetic retinopathy was confined to men with screening blood glucose levels of $11.1 \mathrm{mmol} / 1$ or more when studied 6-8 years after the survey [8]. Significant diurnal variation in oral glucose tolerance was reported in the Whitehall study [7], but this was most evident in men with normal morning glucose tolerance. With high screening cut-off values (in excess of $10.0 \mathrm{mmol} / \mathrm{l}$ ) it appears that diurnal variation would little affect the proportion of positive results, but the study reported [7] was not specifically designed to investigate this point.

As stated in the introduction, the Screening Workshop did not recommend screening programmes to detect asymptomatic glucose intolerance. This recommendation resulted principally from the uncertainty regarding diagnostic criteria plus the lack of evidence concerning objective benefit from the treatment of asymptomatic diabetes. However, as there is now some consensus regarding diagnostic criteria, and as photocoagulation has been shown to prevent the visual deterioration associated with certain kinds of diabetic retinopathy, it is now opportune to re-open the debate about screening. At present there are virtually no data concerning the economic costs and putative benefits of screening. The post-prandial blood glucose screen in capillary blood is relatively inexpensive and non-disruptive. However, the sensitivity and specificity of the method remain to be established against the 'gold standard' of the WHO criteria. Furthermore, our data refer to working, and therefore relatively healthy, populations; they certainly cannot be considered representative of the age groups over 60 years, which are subject to selective retirement. Despite these reservations, we feel that the method deserves further study and hope that the data provided will prove useful to others contemplating the evaluation of blood-glucose screening programmes.

\section{References}

1. Herron CA (1979) Screening in diabetes mellitus: report of the Atlanta Workshop. Diabetes Care 2: 357-362

2. Hall T (1974) Health screening. Comm Health 6: 41-45

3. Reid DD, Brett GZ, Hamilton PJS, Jarrett RJ, Keen $H$, Rose G (1974) Cardiorespiratory disease and diabetes among middle-aged male civil servants: a study of screening and intervention. Lancet 1: 469-474

4. WHO Expert Committee on Diabetes Mellitus (1980) Second Report. Technical Report Series 646, World Health Organization, Geneva

5. Suarez L, Barrett-Connor E (1982) Seasonal variation in fasting plasma glucose levels in man. Diabetologia 22: 250-253

6. Mitchell FL, Strauss WT (1964) Relation of postprandial blood-glucose level to the oral glucose-tolerance curve. Lancet 1: 1185-1189

7. Jarrett RJ, Keen H (1970) Further observations on the diurnal variation in oral glucose tolerance. Br Med J 4: 334-337

8. Al Sayegh H, Jarrett RJ (1979) Oral glucose tolerance tests and the diagnosis of diabetes: results of a prospective study based upon the Whitehall Survey. Lancet 2: 431-433

Received: 29 March 1984

and in revised form: 6 August 1984

Professor R.J.Jarrett

Department of Community Medicine

United Medical and Dental Schools (Guy's Campus)

London, SE1 9RT

UK 